\title{
Morphological Studies on the Third Eyelid and its Related Structures in the One-Humped Camel (Camelus dromedarius)
}

\section{Saeed Y. Al-Ramadan ${ }^{*}$, Abdelhadi M. Ali}

Department of Anatomy, College of Veterinary Medicine and Animal Resources, King Faisal University

\section{Abstract}

The objective of the study was to characterize the macro- and microscopic features of the third eyelid, also called the nictitating membrane, and associated structures in the one-humped camel. The texture, length, thickness, and width of the normal third eyelid were studied in adult camels of both sexes. The results showed that the third eyelid of the camel was formed of a relatively large semilunar fold of conjunctiva that extended up to $3 \mathrm{~cm}$ from the medial canthus of the eye, over the anterior surface of the globe. Histological examination revealed that the third eyelid of the camel was formed of glandular and lymphoid tissues that were enveloped by fibrous connective tissue and supported by a cartilaginous plate. Both the bulbar and palpebral surfaces of the third eyelid were covered with stratified squamous nonkeratinized epithelium. Many goblet cells were interspersed among the epithelial cells that covered the bulbar surface, especially near the base of the third eyelid. The stroma underneath the epithelium was composed of fibrous connective tissue that was infiltrated with different types of leukocytes and that surrounded glandular tissue and lymphoid nodules. The cartilage that supported the third eyelid was of the elastic type and formed of two parts. A Tshaped segment of cartilage existed within the membrane of the third eyelid and a root-shaped appendix was embedded within the gland of the third eyelid. The gland of the third eyelid was also examined and it was found to be a tubuloalveolar mucous gland.

\section{Key words}

Third eyelid, nictitating membrane, lacrimal gland, camel, microscopy 


\section{Introduction}

The camel inhabits arid and semiarid areas and its eyes are important for its survival. In studies of the adaptability of the camel, it is necessary to define the structural features of the third eyelid, the nictitating membrane, which is a prominent semilunar fold of the conjunctiva that is situated at the medial angle of the eye. The third eyelid is important for the production and distribution of tears, the removal of ocular debris, and the protection of the eye, and has significant immunologic functions (Schlegel et al., 2003). Movement of the third eyelid is passive, owing to the absence of muscles that could move the eyelid actively. The location of the free margin of the third eyelid is controlled by the position of the eyeball.

Several studies have been conducted on the eye of the camel and its related structures (Abou-Elmagd 1992; Wang 2002; Kumar et al 2003; Mohammadpour 2009). However, to the authors' knowledge, no detailed study has been performed on the structure of the third eyelid. Thus, the aim of the present study was to investigate the morphological and histological features of the third eyelid and its associated structures in the one-humped camel. The findings will enrich the comparative anatomy of domestic animals, provide a basis for further research on the adaptability of this animal to the desert environment, and might have clinical applications.

\section{Materials and Methods}

Morphological examinations of the third eyelid were conducted on ten clinically healthy adult camels of both sexes at the Al-Omran Slaughter House, Al-Ahsa, Saudi Arabia. The macroscopic preparations were performed using a magnifying lens. The samples were bathed in 60$80 \%$ alcohol and $0.5-4 \%$ acetic acid solution to increase the visibility of the anatomical elements. For the histological examination, the whole eyeball with its accessory structures was collected from each camel immediately after slaughter. The materials collected were fixed in $4 \%$ buffered formaldehyde solution, washed in running water for $24 \mathrm{~h}$, dehydrated in a graded series of alcohol (70-100\% alcohol for $18 \mathrm{~h}$ ), embedded in paraffin, and cut into longitudinal sections that were $5-\mu \mathrm{m}$ thick with a Leica RM 2045 microtome (Microsystem $\mathrm{GmbH}$, Wetzler, Germany). The sections were stained with hematoxylin - eosin (H\&E), Orcein, and Masson trichrome. The sections were evaluated using a light microscope at magnifications of $5 \times, 10 \times, 40 \times$, and 
$100 \times$. Histological images were obtained with an Olympus BX 41 microscope and Olympus DP-12 digital camera (Olympus Corp., Tokyo, Japan).

For macroscopic investigation of the cartilage of the third eyelid, a modification of the maceration technique described by Schlegel et al. (2001) was used. Briefly, the third eyelid was macerated carefully in an aqueous solution of $2 \%$ sodium base for a maximum of $18 \mathrm{~h}$ at $40^{\circ} \mathrm{C}$, which was observed periodically. After maceration, the samples were washed three times in phosphate buffered saline $(\mathrm{pH} \mathrm{6.8)}$ and conserved subsequently in $0.15 \%$ formalin. All samples were photographed with a Sony a-550 camera (Sony Corp., Pathumthani, Thailand).

\section{Results}

The third eyelid of the camel was formed of a relatively large semilunar fold of conjunctiva that extended up to $3 \mathrm{~cm}$ from the medial canthus of the eye, into the anterior surface of the globe. The marginal part of the third eyelid was thin and pigmented (Fig. 1). Both the bulbar and palpebral surfaces were covered with stratified squamous nonkeratinized epithelium (Fig. 2). Many goblet cells were interspersed among the epithelial cells that covered the bulbar surface, especially near the base of the third eyelid (Fig. 3). The stroma beneath the epithelium was formed of fibrous connective tissue which was infiltrated with different types of leukocyte and surrounded the glandular tissue and lymphoid nodules (Figs 3, 4 and 5). In all the specimens examined, no muscle fibers were detected within the third eyelid.

The third eyelid of the camel was supported by a cartilage. The cartilage was dissected carefully and found to be composed of two parts: a T-shaped segment within the membrane of the third eyelid and a root-shaped appendix embedded within the gland of the third eyelid. The T-shaped segment comprised a cross-bar that was parallel to the free margin of the third eyelid and a long narrow shaft that continued caudally as the root-shaped part, which was embedded in the gland of the third eyelid (Fig. 6). Orcein staining revealed that the cartilage was of the elastic type (Fig. 4).

Macroscopically, the gland of the third eyelid was oval in shape with a convex palpebral surface and a concave bulbar surface (Fig. 7). Microscopically, the gland was found to be a tubuloalveolar in type and mucous in nature (Fig. 8). Two 
types of secretory units could be defined: acini with a small lumen, which were lined with tall pyramidal cells, and tubules with a large lumen, which were lined with cuboidal epithelial cells. Elongated nuclei were observed frequently around the acini. Intralobular ducts could also be detected, lined with cuboidal to short columnar cells with large lumens (Fig. 8).

\section{Discussion}

The results of this study revealed that the third eyelid of the adult onehumped camel was formed of a relatively large semilunar fold of conjunctiva that extended up to $3 \mathrm{~cm}$ from the medial canthus of the eye, over the anterior surface of the globe. Movement of the third eyelid is achieved by the forces which are generated when the animal shuts its upper and lower eyelids (Getty, 1975 in domestic animals; Umeda et al., 2010 in canines). Several protective functions that are important for the globe of the eye have been attributed to the third eyelid, such as the production and spread of tears, removal of foreign materials, and immunological activity involving the secretion of immunoglobulins (Kleckowska-Nawrot and Dziegiel, 2007; 2008 in the pig; Alexandre-Pires et al, 2008 in the dog; Mohammadpour, 2009 in the camel; Bay- raktaroğlu and Ergün, 2010 in the Angora rabbit). These functions seem to be particularly important for animals that live in the desert, where sand storms are very common. Such animals need the extra protection for the eyes that is provided by a well-developed third eyelid.

The present study revealed the presence of many goblet cells at the bulbar surface of the third eyelid. In dogs, removal of the third eyelid leads to qualitative changes in the tears, including reduction of the basal tear volume and an increase in $\mathrm{pH}$. In addition, a decrease in the layers of superficial cells and detachment of hemidesmosomes in the basal cell layers of the cornea have been reported (Saito et al., 2004). These findings suggest that the nictitating membrane might play a more important role than was previously thought in protecting the ocular surface, because the mucin produced by the goblet cells might affect the stability of the tear film (Saito et al., 2004; Umeda et al, 2010).

Morphologic observation of the specimens in the present study revealed that the cartilage of the third eyelid in the camel had two parts: a T-shaped segment within the membrane of the third eyelid and a root- 
shaped part embedded within the gland of the third eyelid. The Tshaped segment comprised a crossbar that lay parallel to the free margin of the third eyelid and a long narrow shaft that continued caudally as the root-shaped appendix, which was rooted within the gland. In all domestic mammals studied, the third eyelid is supported by a cartilage, which shows various shapes and forms (Getty, 1975). In pigs and cattle, it has a typical anchor form. In the dog, it has a prominent appendix, which is cone-shaped at the basal end and then extends in a slightly curved form, becomes continually broader, and finally forms a triangular plate with a crescent-like crossbar. In contrast, the cartilage of the third eyelid of the cat has a paddle-shaped proximal part that becomes thinner over a short distance and extends to a triangular plate in the distal direction; the cross-bar has a reverse S-form. The cartilage of small ruminants begins as a thin rod, extends in a distal direction in a slightly curved form, and ends in an oval plate, whereas its cross-bar has a crescent-like shape (Schlegel et al., 2001).

Histological examination of the cartilage of the third eyelid of the camel showed it to be of the elastic type. This is contrary to Mohammadpour, 2009 who described it to be formed of hyaline cartilage. The finding of the elastic cartilage in the camel is not an exceptional one. A similar type of cartilage has been reported in the third eyelid of the cat and horse, whereas hyaline cartilage has been reported in dogs, cattle, and small ruminants (Bank, 1993, Schlegel et al., 2001).

The current study showed that the gland of the third eyelid of the camel was oval in shape with a convex palpebral surface and a concave bulbar surface, and was found to be a tubuloalveolar serous gland. Similar data have been reported previously for the camel (Kumar et al., 2003; Mohammadpour, 2009). In accordance with previous studies conducted on the Harderian glands of camels (Abou-Elmagd, 1992; Kumar et al., 2003), an intralobular duct lined with a single layer of cuboidal to low columnar epithelium was observed between the glandular acini. Similar findings have also been reported in other mammals (Sakai and Yohro, 1981; Gargiulo et al., 1999; Pinard et al., 2003; Munkeby et al., 2006; Rehorek and Smith, 2006). However, in some desert rodents, only tubular units have been reported (Djeridane, 1992). The elongated nuclei around the acini might represent the nuclei of myoepithelial cells. Electron microscopy has revealed the presence of 
myoepithelial cells between the lining glandular cells and the basal lamina in the Harderian gland of the camel (Abou-Elmagd, 1992; Kumar et al., 2003) and the rabbit (Bayraktaroglu and Ergun 2010).

\section{Acknowledgements}

This work was supported by the Scientific Research Deanship, King Faisal University (Grant No. 10136). Our thanks to the staff at Al-Omran Slaughter House, Alahsa, Saudi Arabia.

\section{References}

Abou-Elmagd, A. (1992): Ultrastruc tural observations on myoepithliel cells and nerve terminals in the camel Harderian gland. Anat. Embryol. 185, 501-507.

Alexandre-Pires, G., M. C. Alguero, $\mathrm{L}$. Mendes-Jorge, and $\mathrm{H}$. Trindade, (2008): Immunophenotyping of lymphocytes subsets in the third eyelid tissue in dogs (Canis familiaris): Morphological, microvascular, and secretory aspects of this ocular adnexa. Microsc. Res Tech. 69, 227-235.
Bank WJ., (1993): Applied veteri nary histology. Mosbi Inc. St. Louis, Missouri, USA. pp 416.

Bayraktaroglu, A. G. and E. Ergun (2010): Histomorphology of the Harderian gland in the Angora rabbit. Anat. Histol. Embryol. 39, 494-502.

Djeridane, Y., (1992): The harderian gland of desert rodents: A histological and ultrastructural study. J. Anat. 180, 465-480.

Gargiulo, A.M., P. Coliolo, P. Cec carelli, and V. Pedini, (1999): Ultrastructural study of sheep lacrimal glands. Vet Res. 30, 345-51

Getty, R., (1975): Sisson and Grossman's The Anatomy of the Domestic Animals. (5th ed). Philadelphia London Toronto: W. B. Saunders Company, pp. 1411.

Kleckowska-Nawrot, J., and

Dziegiel P., (2007): Morphology of the third eyelid and superficial gland of the third eyelid on pig fetuses. Anat. Histol. Embryol. 36, 428-432.

Kleckowska-Nawrot, J., and

Dziegiel P., (2008): Morphology of Deep Gland of the Third Eyelid in Pig Foetuses. Anat. Histol. Embryol. 37, 36-40. 
Kumar, P., R. K. Jain, and A. N.

Gupta (2003): Histoarchitecture of Harderian gland of camel (Camelus dromedaries). Indian. J. Anim. Sci.

73, 972-975.

Mohammadpour, A. A., (2009):

Morphological and histological study of superior lacrimal gland of third eyelid in camel (Camelus dromedarius). Iran J. Vet. Res. 10, 334-338.

Munkeby, B.N., H. Smith, E. H.

Winther-Larssen, A. Bjornerud, and I. Bjerkas, (2006) : Magnetic resonance imaging of the Harderian gland in piglets. J. Anat. 209, 699705.

Pinard, C. L., M. L. Weiss, A. H.

Brightman, B. W. Fenwick, and H. J. Davidson, (2003): Normal anatomical and histochemical characteristics of the lacrimal glands in the American bison and cattle. Anat. Histol. Embryol. 32, 257-262.

Rehorek, S. J., and T. D. Smith, (2006): The primate Harderian gland: Does it really exist? Ann Anat. 188, 319-327.

Saito, A., Y. Watanabe, and T. Kotani, (2004): Morphologic changes of the anterior corneal epithelium caused by third eyelid removal in dogs. Vet Ophthalmol. 7, 113-119. Sakai, T., and T. Yohro, (1981): A histological study of the Harderian gland of Mongolian gerbils, Meriones meridianus . Anat Rec. 200, 25970.

Schlegel, T., H. Brehm, and W. M. Amselgruber, (2001): The cartilage of the third eyelid: A comparative macroscopical and histological study in domestic animals. Ann. Anat. 183, 165-169.

Schlegel, T., H. Brehm and W. M. Amselgruber, (2003): IgA and secretory component (SC) in the third eyelid of domestic animals: A comparative study. Vet Ophthalmol. 6, 157-161.

Umeda, Y., S. Nakamura, K. Fujiki , H. Toshida, A. Saito, and A. Murakami (2010): Distribution of goblet cells and MUC5AC mRNA in the canine nictitating membrane. Exp. Eye Res. 91, 721-726.

Wang, J., (2002): The arterial sup ply to the eye of the Bactrian camel (Camelus bactrianus). Vet. Res. Commun. 26, 505512.

Corresponding author:

Tel.: 966358 16600; Fax: 966358 16635; e-mail: salramadan@kfu.edu.sa 
The third eyelid of the one- humped camel

Al-Ramadan and Ali

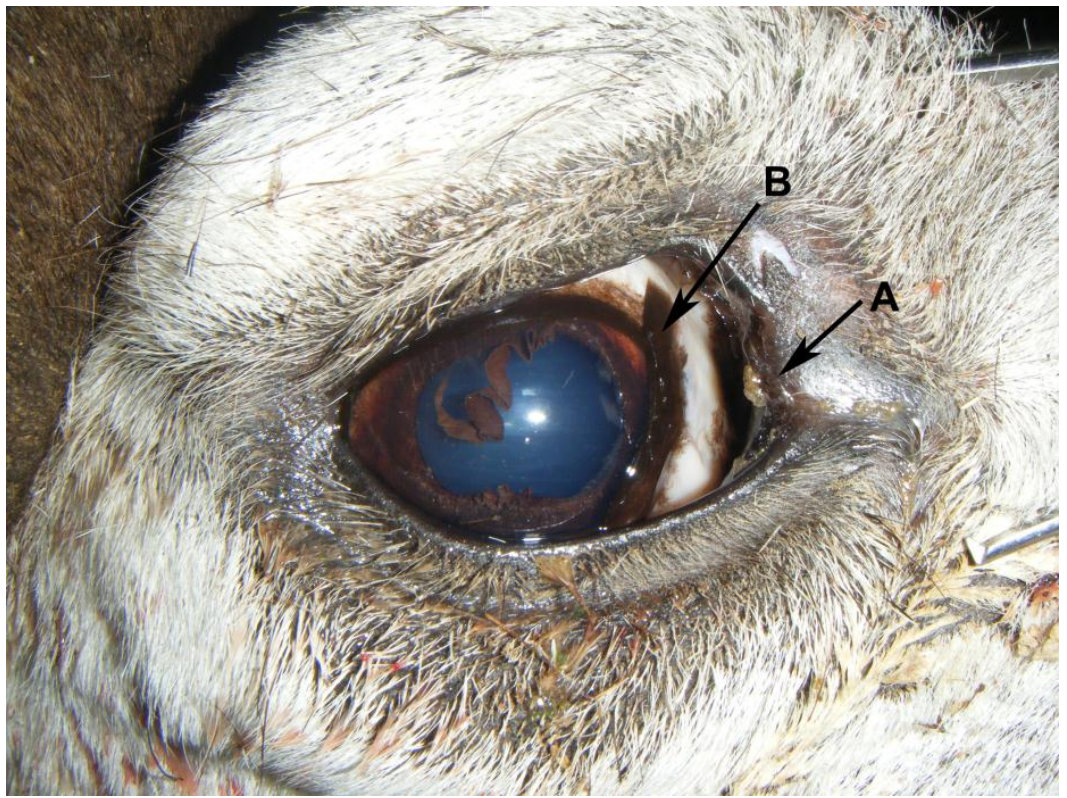

Fig (1): The third eyelid of the camel extends from the medial canthus of the eye (A). Note the marginal pigmented portion (B).

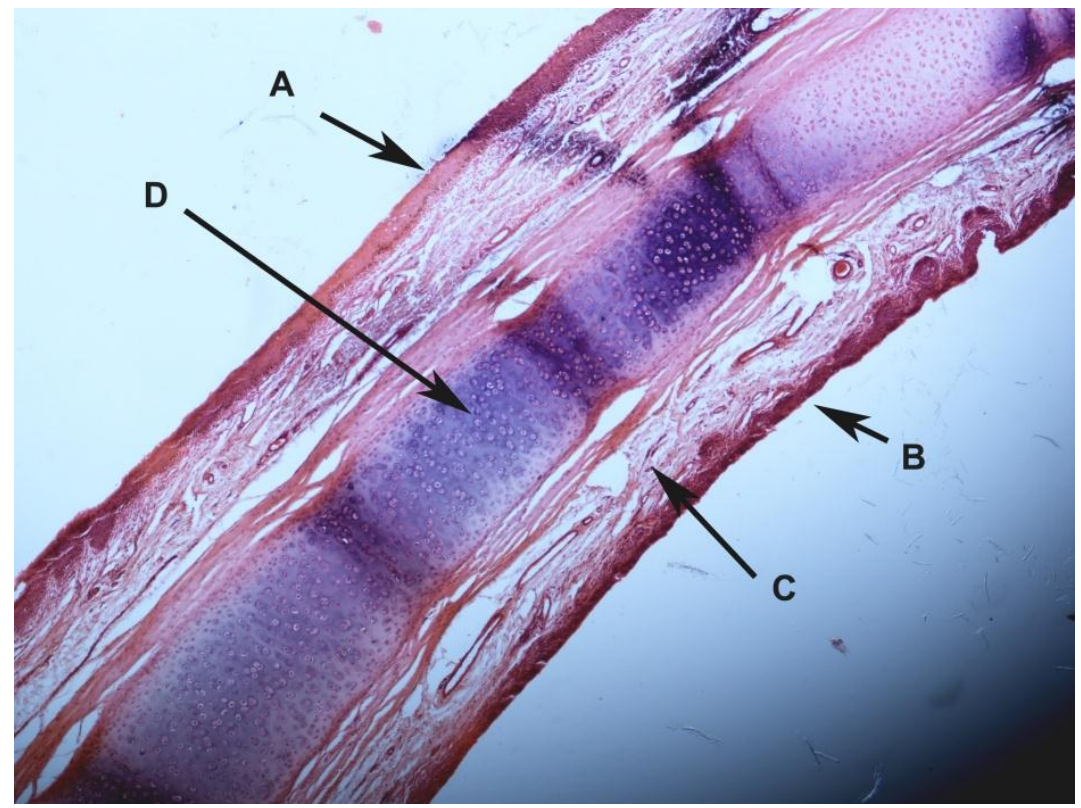

Fig (2): Light micrograph of the third eyelid showing the anterior (A) and posterior (B) surfaces, with the connective tissue stroma (C) and the cartilage (D) (H\&E, X40). 


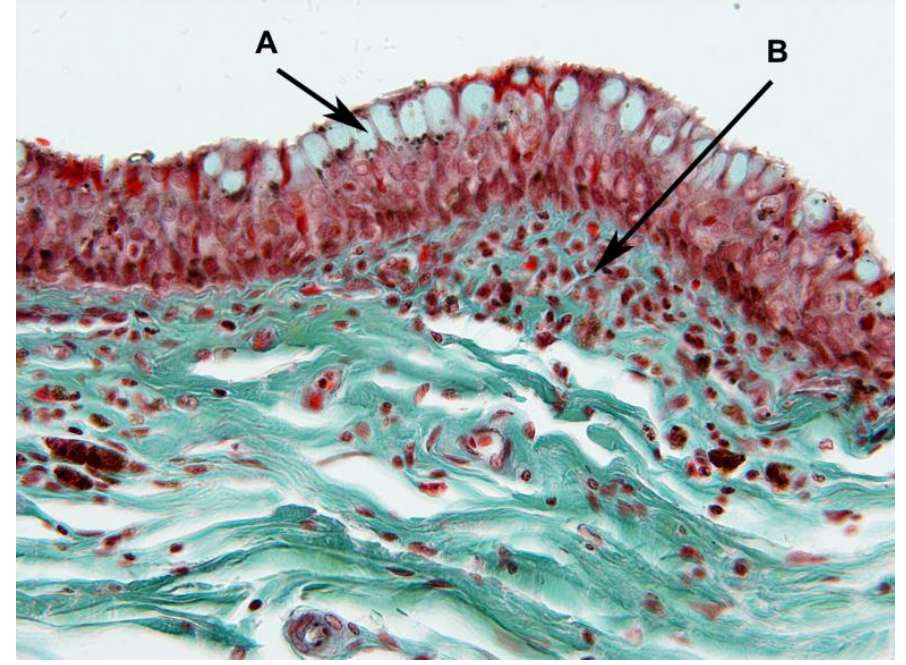

Fig (3): Light micrograph showing the posterior surface of the third eyelid near its base. Note the goblet cells (A) within the stratified squamous epithelial layer. The stroma of fibrous connective tissue is infiltrated with different types of leukocyte (B) (Trichrome, $\mathrm{X} 400)$.

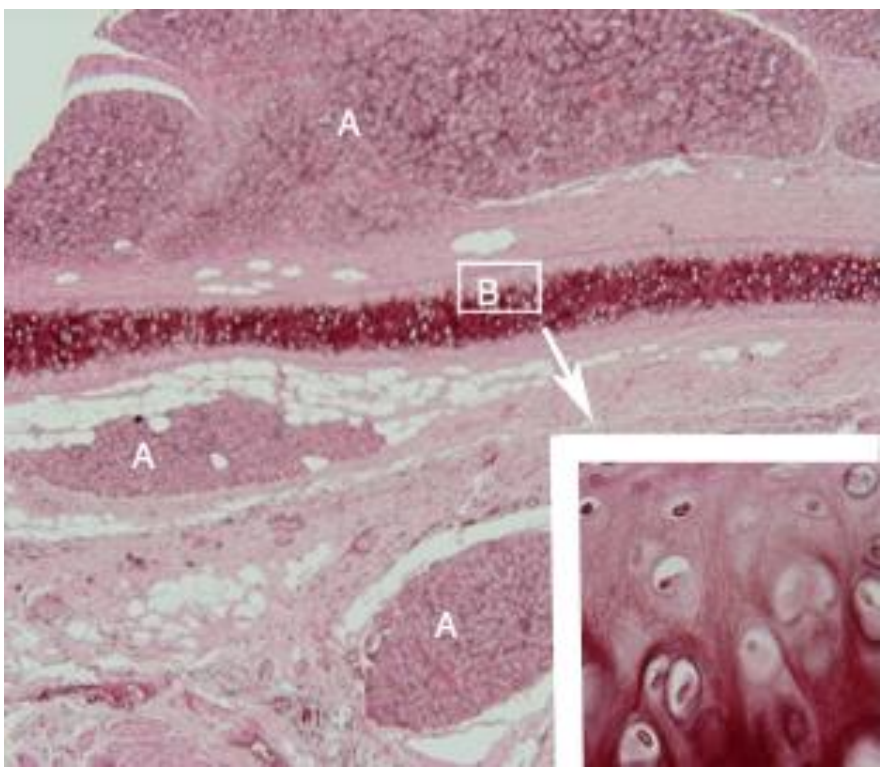

Fig (4): Light micrograph of the third eyelid of the camel. Note the glandular components of the gland of the third eyelid (A) and the cartilage bar (B) that is rooted deeply in the gland (Orcein, 40x). Insert: higher magnification of (B); note the condensation of the elastic fibers (X400). 


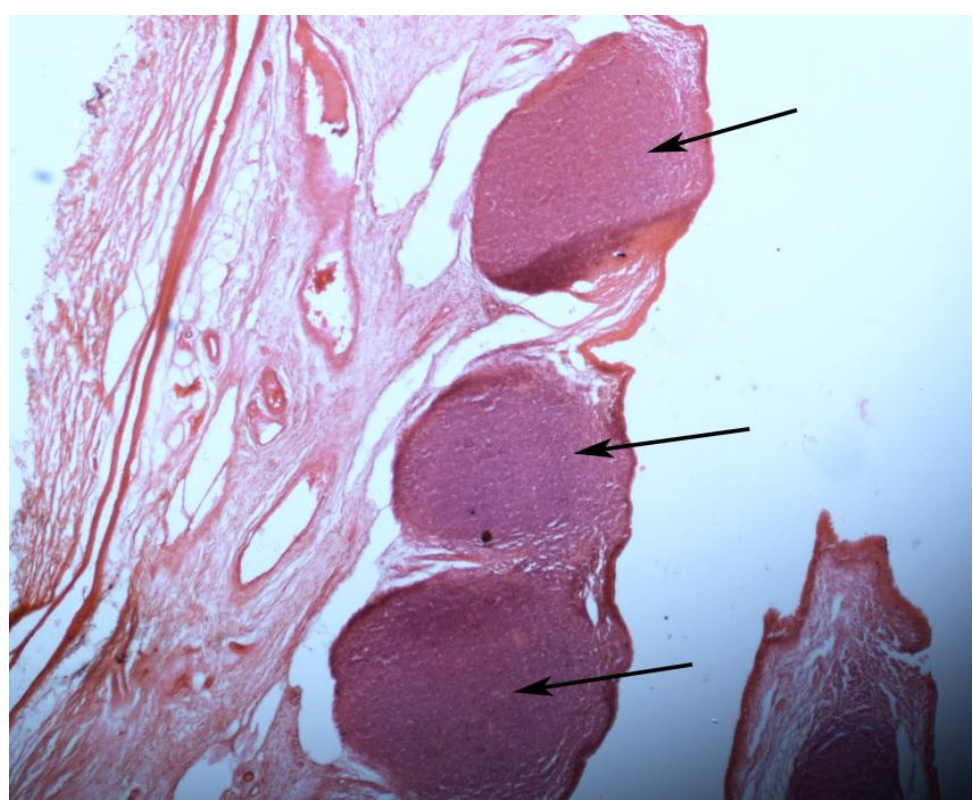

Fig (5): Light micrograph showing the lymphatic nodules (arrows) that were detected near the base of the third eyelid of the camel (H\&E, X100).

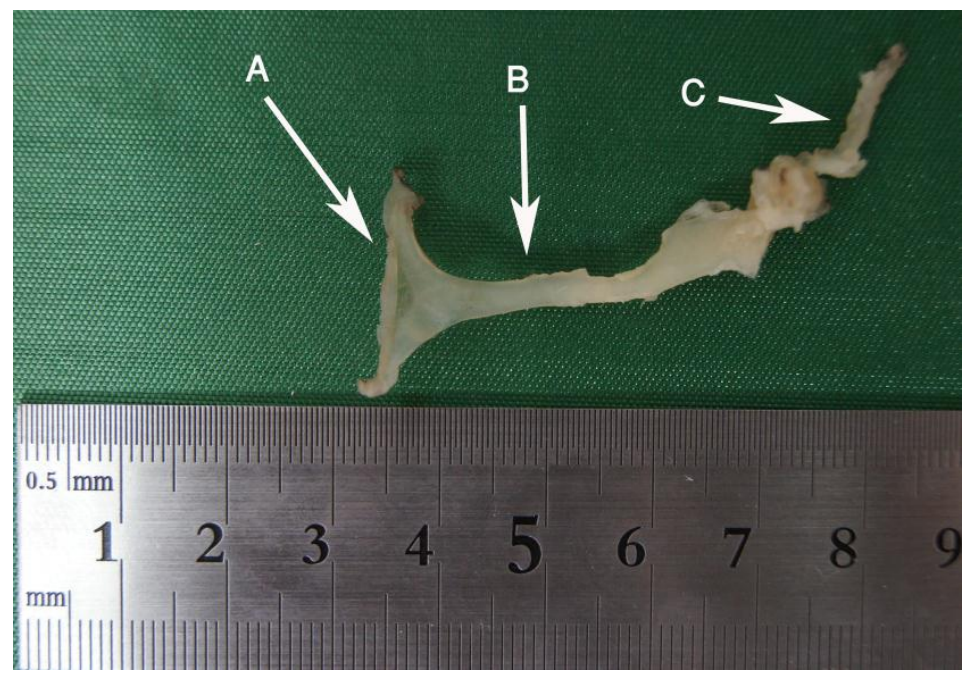

Fig (6): A photograph showing the cartilage of the third eyelid. Note the T-shaped segment with its cross-bar (A) and long narrow shaft $(B)$, which continue as a branched segment $(C)$ within the gland of the third eyelid. 

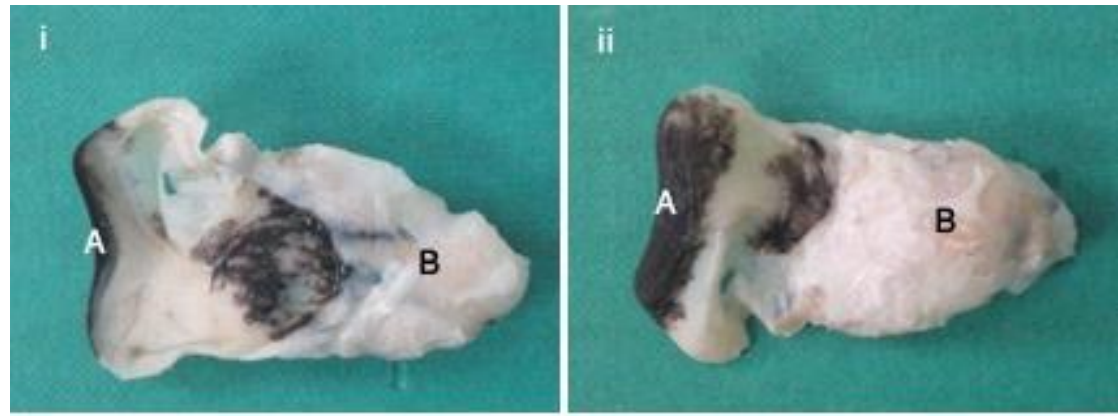

Fig (7): The third eyelid of the camel with its associated structures: (i) bulbar surface, (ii) palpebral surface. Free margin of the third eyelid (A), gland of the third eyelid (B).

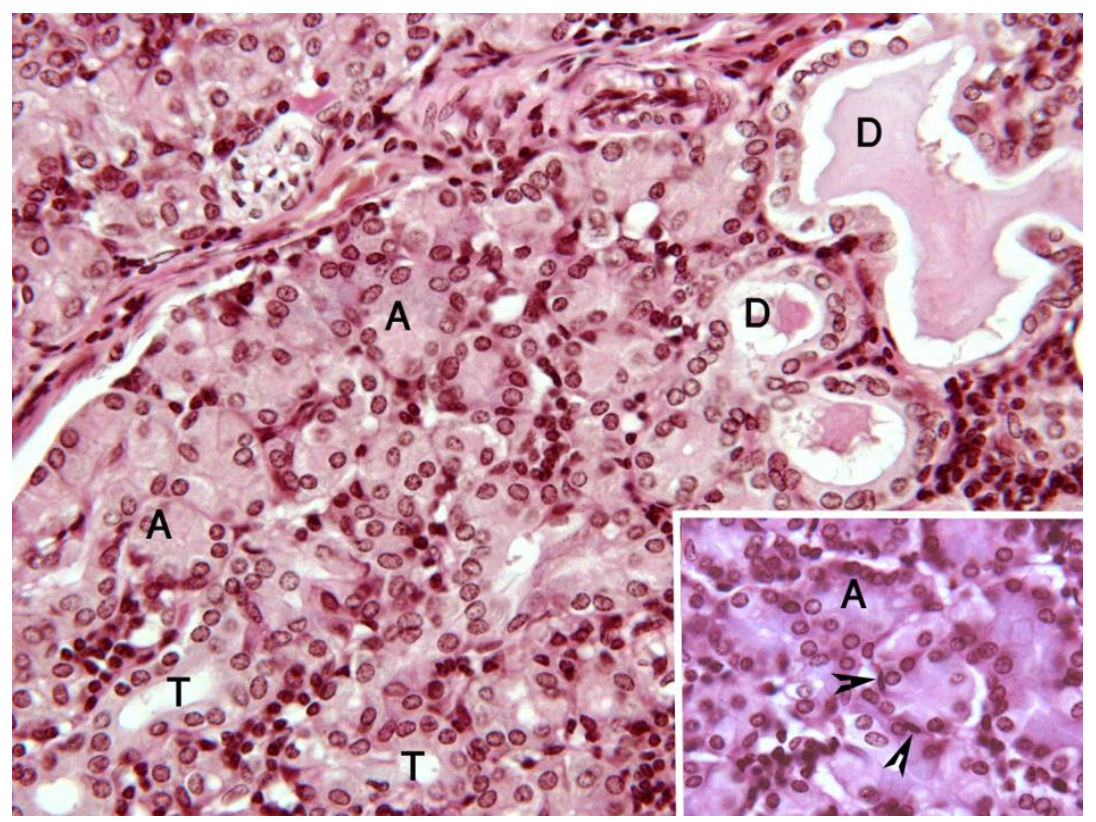

Fig (8): Light micrograph of the gland of the third eyelid of the camel, showing tubuloaloveolar units with acini (A) lined by pyramidal cells, and tubules (T) lined with cuboidal to low columnar cells surrounding an empty lumen; (D) intralobular ducts (Orcein, $\times 100$ ). Insert: higher magnification of the field, note the elongated nuclei (arrow heads) at the base of the acini (X400). 


\section{Animal species in this issue}

\section{One-humped camel (Camelus dromedarius)}

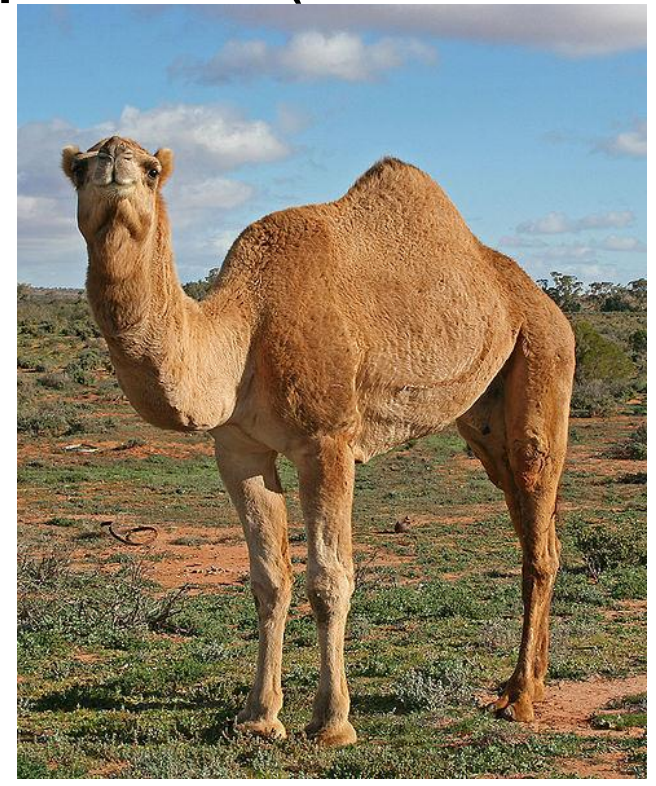

Kingdom: Animalia, Phylum: Chordata, Class: Mammalia, Oder: Artiodactyla. Family: Camelidae, Genus: Camelus

Camel is an even-toed ungulate within the genus Camelus, bearing distinctive fatty deposits known as humps on its back. There are two species of camels: the dromedary or Arabian camel has a single hump, and the Bactrian camel has two humps. They are native to the dry desert areas of West Asia, and Central and East Asia, respectively. Both species are domesticated to provide milk and meat, and as beasts of burden.

The average life expectancy of a camel is 40 to 50 years. A fully grown adult camel stands $1.85 \mathrm{~m}$ at the shoulder and $2.15 \mathrm{~m}$ at the hump. The hump rises about 30 inches $(76.20 \mathrm{~cm})$ out of its body. Camels can run at up to $65 \mathrm{~km} / \mathrm{h}(40 \mathrm{mph})$ in short bursts and sustain speeds of up to $40 \mathrm{~km} / \mathrm{h}(25 \mathrm{mph})$.

Fossil evidence indicates that the ancestors of modern camels evolved in North America during the Palaeogene period, and later spread to most parts of Asia. Humans first domesticated camels before $2000 \mathrm{BC}$.

Camels are able to withstand changes in body temperature and water content that would kill most other animals. Their temperature ranges from $34{ }^{\circ} \mathrm{C}$ at night and up to $41^{\circ} \mathrm{C}$ during the day, and only above this threshold will they begin to sweat.

(Source: Wikipedia) 